\title{
$\mathrm{SRM}$ 의 가변속 구동을 위한 퍼지 PI 제어기 설계
}

\section{Design of Fuzzy PI Controller for Variable Speed Drive of Switched Reluctance Motor}

윤 용 호 ${ }^{*}$ 박 준 석** 송 상 훈*** 원 충 연 · 김 재 문 ${ }^{+}$

(Yong-Ho Yoon $\cdot$ Jun-Suk Park $\cdot$ Sang-Hoon Song $\cdot$ Chung-Yuen Won $\cdot$ Jae-Moon Kim)

\begin{abstract}
This paper presents the application algorithm for speed control of Switched Reluctance Motor. The conventional PI controller has been widely used in industrial applications. But it is very difficult to find the optimal PI control gain. Fuzzy control does not need any model of plant. It is based on plant operator experience and heuristics. The proposed fuzzy logic modifier increases the control performance of conventional PI controller. Simulation and experimental results show that the proposed fuzzy control method was superior to the conventional PI controller in the respect of system performance. The experiments are performed to verify the capability of proposed control method on $6 / 4$ salient type SRM.
\end{abstract}

Key Words : SRM, PI control, Fuzzy control, Hysteresis current control

\section{1. 서 론}

$\mathrm{SRM}$ 은 전류의 크기와 회전자와 고정자의 상대적 위치에 따라 인덕턴스가 매우 비선형적으로 변하는 특성을 지니고 있고 토오크는 이 인덕턴스의 기울기에 비례하여 발생하기 때문에 비선형 토오크 특성을 가지며 토오크 맥동이 크고 소음이 심한 단점이 있어 실용화에 큰 장애가 되어 오고 있 다. 이로 인해 제어하기 위한 제어회로와 고속 스위칭을 하 기 위한 구동장치가 복잡해 실용화되지 못하다가 최근에 고 속 대전력용 스위칭 소자의 값싼 개발과 전력전자 기술의 발달로 급속한 발전을 이루게 되었다[1-2].

$\mathrm{SRM}$ 의 가변속 구동에 많이 사용되고 있는 PI 제어기의 경우 알고리즘이 간단하여 아날로그 제어기로도 쉽게 구현 이 가능하고, 제어 이득값이 적절히 조정될 경우 좋은 운전 특성을 지니는 장점을 가지고 있다. 그러나 운전점이 달라 지거나 시스템의 파라미터가 변하는 경우 제어 이득값을 적 절히 조정해 주어야 하는 문제가 있다. 특히 SRM의 비선형 인덕턴스 특성을 지니는 이유로 수학적 모델링이 불가능하 고, 정상상태에서의 등가회로가 존재하지 않기 때문에 적절 한 제어 이득값을 얻는데 있어 실험적인 방법에 의존하고 있다[3]. 이러한 단점을 보완하기 위하여 인간의 판단방법과 유사한 애매모호한 결정에 대한 것도 확률적으로 결정할 수 있도록 한 fuzzy 제어방법과 일종의 학습 제어 방식인 신경 망을 이용한 방법도 많이 활용되고 있다. 이밖에도 가변 구

\footnotetext{
* 정 회 원 : 한국산업기술시험원 선임연구원 · 공박

** 정 회 원 : 한국산업기술시험원 수석연구원 · 공박

*** 정 회 원 : 한국산업기술시험원 책임연구원 - 박사수료

$\S$ 시니어회원 : 성균관대학교 정보통신공학부 교수·공박

$\uparrow$ 교신저자, 정회원 : 한국교통대학교 철도전기전자공학과

$$
\text { 부교수 · 공박 }
$$

E-mail：goldmoon@ut.ac.kr

접수일자 : 2012년 8월 3일

최종완료 : 2012년 9월 24일
}

조제어 등과 같은 방법들이 이용되어 지고 있다.

본 논문에서는 가변속 구동을 위하여 PI 제어의 형태를 갖는 fuzzy 제어기를 구성하여 시뮬레이션 및 실험을 통하 여 기존의 PI 제어기에서 사용한 경우와 비교하였다. Fuzzy 제어기의 제어 알고리즘은 지령속도에 근접했을 때 오차 범 위를 줄이기 위해 속도 오차가 작아질 때부터는 미세 제어 가 가능하도록 설계하여 정상상태에서의 채터링 현상을 줄 이고, 파라미터 변화와 외란에 둔감한 강인한 특성을 갖도록 하였다. 또한 실시간 제어에 적합하도록 각각의 입력에 대 한 출력값을 미리 계산하여 look-up table로 저장하고 부적 절하게 설계된 PI 제어기의 제어이득에서도 강인한 제어성 능과 시스템의 안정화 작용을 나타낼 수 있도록 구성하고 시뮬레이션과 실험으로 그 성능을 확인하였다.

\section{2. 속도제어를 위한 fuzzy 제어기 구성}

일반적으로 속도제어기의 대역폭은 응답성이나 안정성을 고려하여 전류제어기에 영향을 주지 않는 범위내에서 설계 하고 속도제어 시스템의 폐루프 전달함수 $G_{S}^{o}(s)$ 는 식 (1)과 같다.

$$
G_{s}^{o}(s)=\frac{\frac{K_{T} K_{p s}}{J} S+\frac{K_{T} K_{i s}}{J}}{S^{2}+\frac{K_{T} K_{p s}}{J} S+\frac{K_{T} K_{i s}}{J}}
$$

식(1)의 속도제어계의 감쇄비 $\xi$ 는 1 보다 크므로 과감쇠가 일어나지만 전달함수 분자의 영점에 영향으로 오버슈트가 발생한다. 이러하 오버슈트는 모터브레이크에 영향을 주어 안정성에 문제를 발생시킨다[3].

많은 실제 시스템에서 수학적 모델을 구하는 것은 매우 
어렵기 때문에 제어하고자 하는 과정에 대한 가장 중요한 정보중의 하나가 진행과정과 제어명령들에 관한 언어적 설 명이 요구되는 지식기반으로부터의 제공이 된다. 이전의 제 어 알고리즘과 달리 fuzzy 제어기는 제어 알고리즘 속에 전 문가로부터 얻어진 언어적 정보와 결합한 체계적이고 효율 적인 구성을 제공하기 때문에 정확한 수학적 모델을 얻기 어려운 $\mathrm{SRM}$ 과 같은 비선형 특성을 갖는 시스템에 가장 좋 은 선택이다.

본 논문에서 SRM 가변속 구동을 위한 fuzzy 제어기는 퍼지화, 퍼지추론, 비퍼지화의 과정으로 진행되며 지령 속도 에 근접했을 때 오차의 범위를 줄여주기 위하여 속도의 오 차가 작아질 때부터는 미세 제어에 들어가도록 설계하였다.

$\omega_{r e f}$ 와 $\omega$ 를 각각 시스템의 지령속도와 실제 속도라고 한 다면, FLM (Fuzzy Logic Modifier)을 통해 나오는 출력은 식 (2)와 같이 나타내어진다[4-6].

$\mathrm{FLM}$ 은 입력변수를 소속함수로 처리하는 과정으로 입력 변수가 소속함수를 통해 관계되는 퍼지집합에 속하는 정도 른 결정한다. 소속함수는 가우시안 분포, 시그모이드 곡선, 범종형, 삼각형 등의 임의의 형태일수 있다. 일단 소속함수 의 형태가 선택되면 중앙값과 변역을 선정한다. 어떠한 순 간에 하나의 규칙이 만족될 수 있게 소속 함수가 중복되도 록 한다.

$$
u_{f u z z y}=K_{f} F_{f u z z y}(e, c e)
$$

여기서, $e$ 는 오차 $\left(e=\omega_{r e f}-\omega\right)$ 이고, $c e$ 는 오차의 변화량 $(c e=d / d t)$ 을 나타낸다. 따라서 fuzzy 제어기의 입력 변수는 식 (3)으로 표현되어진다.

$$
\begin{aligned}
& e(k)=\omega_{r e f}-\omega(k) \\
& c e(k)=e(k)-e(k-1)
\end{aligned}
$$

그리고 $K_{f}$ 는 fuzzy 제어기에서 적절하게 조절되는 1 개의 이득상수이다.

본 논문에서 퍼지 규칙은 퍼지집합 $\mathrm{NB}, \mathrm{PB}, \mathrm{N}, \mathrm{P}$ 에 의해 퍼지-추론되며, 이들의 소속함수는 그림 1 과 같다.

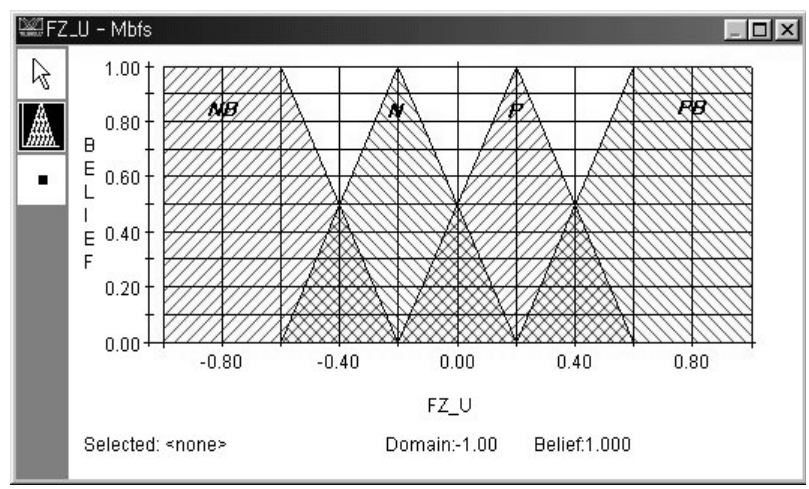

그림 $1 F_{f u z z y}$ 의 소속함수

Fig. $1 F_{\text {fuzzy }}$ function
PI 제어의 형태를 갖는 fuzzy 제어기는 식 (4)와 같이 기 존의 PI 제어기에 퍼지 변형항이 추가된 형태가 된다. 앞에 서 설명한 바와 같이 구성된 fuzzy 제어기의 작용을 자세히 살펴보면 다음과 같다. 먼저 전동기가 목표속도인 $\omega_{r e f}$ 로 속 도를 증가하는 시점에서는 fuzzy 제어기의 제어량을 증가시 켜 전동기가 빠른 시간에 목표속도로 도달할 수 있도록 한 다. 그리고, 전동기의 속도가 목표속도를 벗어나 증가되려 할 때에는 fuzzy 제어기는 전동기의 속도상승을 억제하기 위해 제어량을 급격하게 감소시키게 된다.

또한 전동기의 속도가 목표속도 이하로 떨어질 경우 fuzzy 제어기는 제어량을 급격히 증가시켜 전동기의 속도가 감소하 는 것을 억제하게 된다.

$$
\begin{aligned}
u(t)= & u_{p}(t)+u_{i}(t)+u_{f u z z y}(t) \\
= & K_{p} e(t)+K_{i} \int e(t) d t \\
& +K_{f} F_{f u z z y}(e, c e)
\end{aligned}
$$

이와 같은 fuzzy제어기의 작용으로 전동기의 속도를 기존 의 PI 제어기만을 사용할 경우보다 빠르고 안정적으로 목표 속도에 도달하게 된다.

\section{3. 시뮬레이션}

본 논문에서는 비선형 인덕턴스 특성을 갖는 $\mathrm{SRM}$ 의 시 뮬레이션을 위하여 아래와 같은 가정 하에 시뮬레이션을 하 였다.

(1) $\mathrm{SRM}$ 의 입력측 $\mathrm{DC}$ 링크 전압의 맥동은 무시한다.

(2) SRM은 자기포화가 없다고 가정한다.

(3) 비대칭 브리지 컨버터의 스위치 및 다이오드의 손실은 무시한다.

시뮬레이션은 $\mathrm{C}$ 언어를 사용하였으며 미분 방정식의 해를 구하기 위해 Runge-Kutta 방법을 사용하였고 제어부의 샘 플링 시간은 $50 \mu \mathrm{s}$, fuzzy 제어기기의 구성부분은 퍼지전용 소프트웨어인 TILSHEEL ${ }^{+}$를 사용하였다.

본 논문에서 사용된 $\mathrm{SRM}$ 의 유한요소법에 의한 모델링의 결과 그림 2 와 같은 자속분포도를 보여주고 있으며 시뮬레 이션에 사용된 전동기 상수는 표 1 과 같다

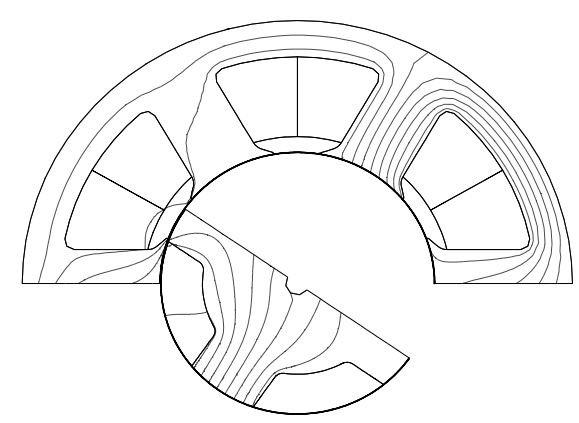

그림 $2 \mathrm{SRM}$ 의 자속분포도 (회전자 위치 $144^{\circ}$ )

Fig. 2 Magnetic flux density of SRM 
표

1 실험에 사용된 전동기 상수

Table 1 Motor parameters for experiments

\begin{tabular}{|c|c|}
\hline 전동기 출력 & $160[\mathrm{~W}]$ \\
\hline 최 대 속 도 & $2,200[\mathrm{rpm}]$ \\
\hline 고정자 극수 & $6[$ 극] \\
\hline 회전자 극수 & $4[$ 극] \\
\hline 권 선 저 항 & $0.04166[\Omega /$ 상] \\
\hline 최대 인덕턴스 & $2.332[\mathrm{mH}]$ \\
\hline 최소 인덕턴스 & $0.241[\mathrm{mH}]$ \\
\hline 고정자 극호 $\left(\beta_{s}\right)$ & $30[\mathrm{deg}]$ \\
\hline 고정자 극호 $\left(\beta_{r}\right)$ & $32[\mathrm{deg}]$ \\
\hline
\end{tabular}

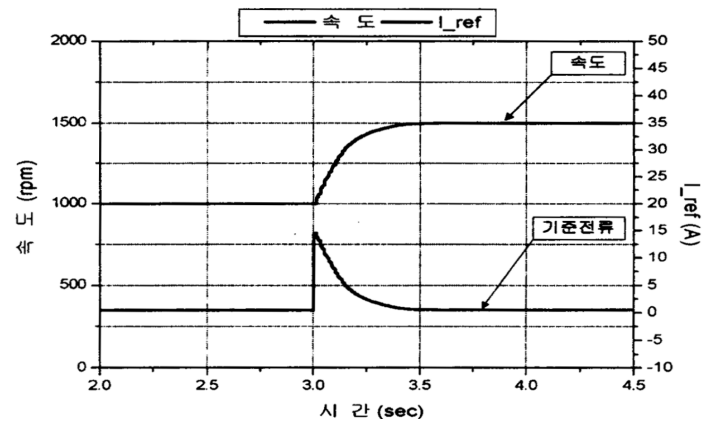

(a) $\mathrm{Pl}$ 제어기

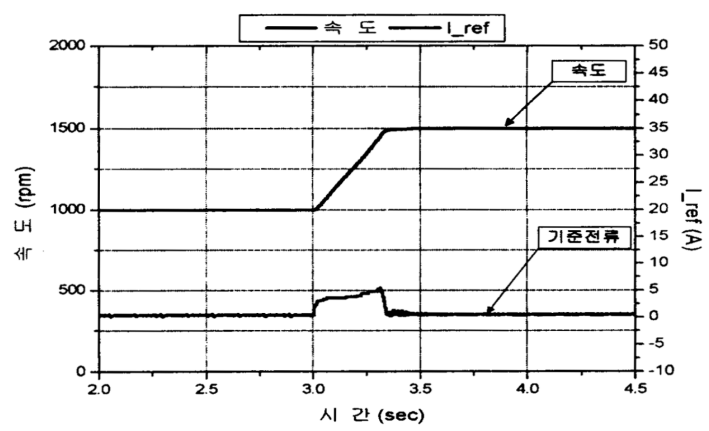

(b) $\mathrm{PI}+$ fuzzy 제어기

그림 3 속도 변화시의 속도응답 (1000rpm $\rightarrow 1500 \mathrm{rpm})$

Fig. 3 Speed response during variable speed operation

그림 3 은 속도 지령치를 $1,000 \mathrm{rpm}$ 에서 $1,500 \mathrm{rpm}$ 으로 바 꾸었을 때의 속도 및 기준전류 파형으로 PI 제어기를 사용 한 경우 정상상태까지의 도달시간이 약 0.4 초가 소요되었고 $\mathrm{PI}+$ fuzzy 제어기를 사용한 경우 0.3 초로 기존의 PI 제어기 에 비해 지령속도에 대한 전체적인 응답이 빨라졌다. 또한 기준 전류의 변화에 있어서는 PI 제어기가 PI + fuzzy 제어 기에 비해서 속도변화 시 많은 오버슈트를 나타내고 있다.

그림 4 는 속도 지령치를 $1,000 \mathrm{rpm}$ 에서 $2,000 \mathrm{rpm}$ 으로 속도 변화를 주었을 때의 속도 및 기준전류 파형이다. PI 제어기 를 사용한 경우 약 1 초가 소요되었고 PI + fuzzy 제어기를 사용한 경우 약 0.7 초가 소요되었다. 기준전류의 변화에 있어 서 PI 제어기의 경우 초기에 많은 오버슈트가 발생한 반면 PI + fuzzy 제어기의 경우 후반부에 나타남을 볼 수 있다.

그림 5 는 속도 지령치를 $1,500 \mathrm{rpm}$ 에서 $1,000 \mathrm{rpm}$ 으로 감 속시의 속도응답 파형으로 PI 제어기를 사용한 경우 약 0.35 초가 소요, PI + fuzzy 제어기를 사용한 경우 거의 오버슈트
없이 약 0.25 초로 정상상태까지의 도달시간이 짧아짐을 보 여주고 있다. 그리고 기준전류의 변화에 있어서는 PI 제어기 와 PI + fuzzy 제어기 모두 다 비슷하게 나타남을 볼 수 있다.

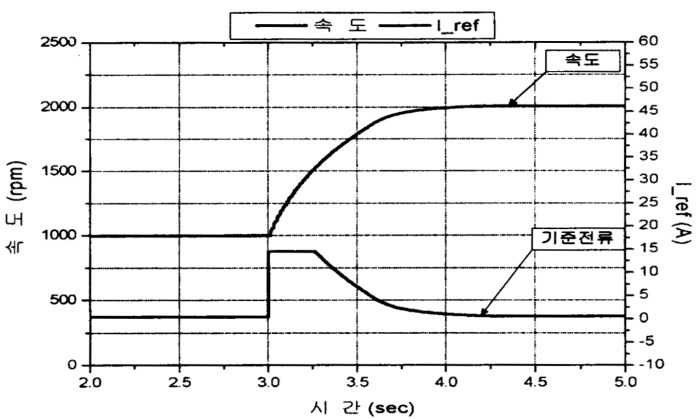

(a) $\mathrm{PI}$ 제어기

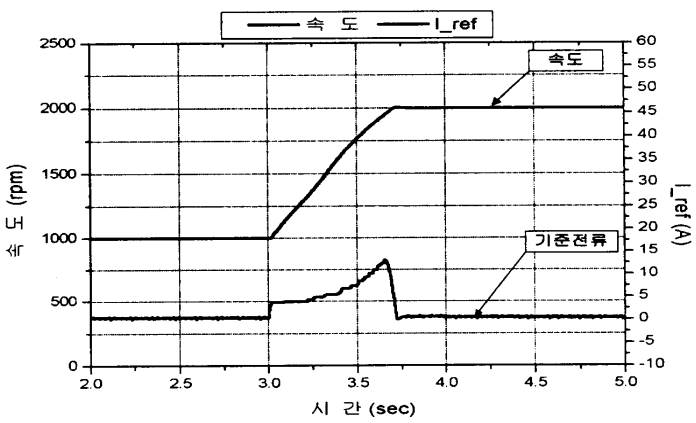

(b) PI + fuzzy 제어기

그림 4 속도 변화시의 속도응답 $(1000 \mathrm{rpm} \rightarrow 2000 \mathrm{rpm})$

Fig. 4 Speed response during variable speed operation

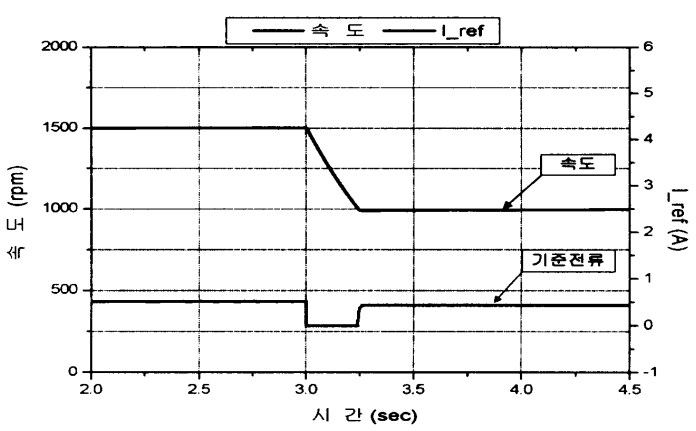

(a) $\mathrm{PI}$ 제어기

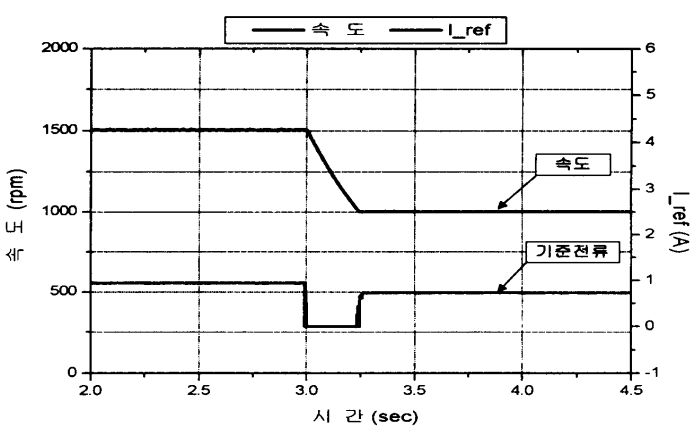

(b) $\mathrm{PI}+$ fuzzy 제어기

그림 5 속도 변화시의 속도응답 $(1500 \mathrm{rpm} \rightarrow 1000 \mathrm{rpm})$

Fig. 5 Speed response during variable speed operation 
그림 6 은 속도 지령치를 $2,000 \mathrm{rpm}$ 에서 $1,000 \mathrm{rpm}$ 으로 감 속시의 속도응답 파형이다. PI 제어기를 사용한 경우 오버슈 트가 발생하며 정상상태까지의 도달시간이 1.2 초가 소요되 는 반면 PI + fuzzy 제어기를 사용한 경우 거의 오버슈트 없이 정상상태 도달시간이 PI 제어기를 사용한 경우의 $1 / 3$ 정도인 0.4 초가 소요되는 결과를 보여주고 있다. 그리고 기 준전류의 변화에 있어서는 PI 제어기와 PI + fuzzy 제어기 모두 다 비슷한 결과를 보여주고 있다.

PI 제어기와 PI + fuzzy 제어기의 시뮬레이션 결과에 대 한 속도응답을 표 2 와 같이 정리를 하였다. 시뮬레이션을 통해 적절한 제어 이득값을 주었을 때의 PI 제어기에서 뿐 만 아니라 오버슈트의 감소와 정상상태에 도달하는 시간이 PI 제어기만을 사용하였을 때보다 단축됨을 알 수 있다. 이 와 같이 PI + fuzzy 제어기의 추가는 피드백 시스템에서 강 인한 시스템 안정화 작용을 하고 시스템의 제어성능을 향상 시키는 작용을 하게 된다.

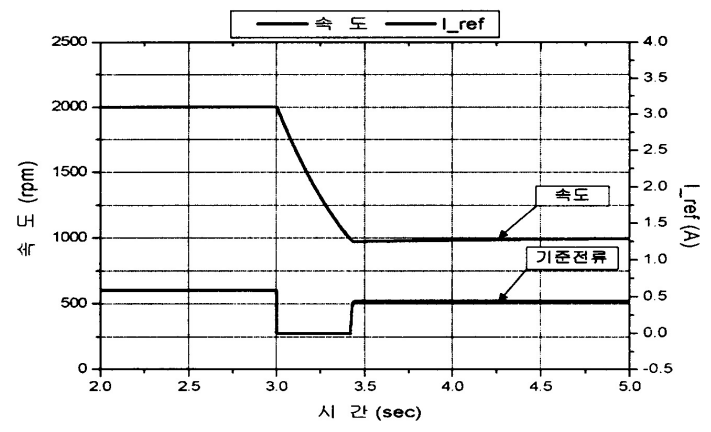

(a) $\mathrm{Pl}$ 제어기

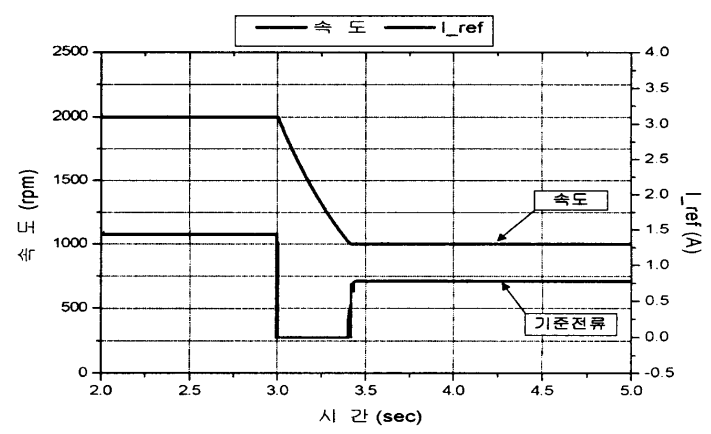

(b) PI + fuzzy 제어기

그림 6 속도 변화시의 속도응답 (2000rpm $\rightarrow 1000 \mathrm{rpm}$ )

Fig. 6 Speed response during variable speed operation

표 2 PI제어기와 fuzzy 제어기의 속도응답

Table 2 Speed response characteristics of PI and fuzzy controller

\begin{tabular}{|c|c|c|c|c|}
\hline \multirow{2}{*}{} & \multicolumn{4}{|c|}{ 무부하시 } \\
\cline { 2 - 5 } & $\begin{array}{c}1,000 \rightarrow \\
1,500\end{array}$ & $\begin{array}{c}1,000 \rightarrow \\
2,000\end{array}$ & $\begin{array}{c}1,500 \rightarrow \\
1,000\end{array}$ & $\begin{array}{c}2,000 \rightarrow \\
1,000\end{array}$ \\
\hline $\begin{array}{c}\mathrm{PI} \\
\text { 제어기 }\end{array}$ & 0.4 초 & 1 초 & 0.35 초 & 1.2 초 \\
\hline $\begin{array}{c}\text { 퍼지 } \\
\text { 제어기 }\end{array}$ & 0.3 초 & 0.7 초 & 0.25 초 & 0.4 초 \\
\hline
\end{tabular}

\section{4. 실험 결과}

본 논문에서는 $\mathrm{SRM}$ 의 가변속 구동을 위하여 $\mathrm{PI}$ 제어의 형태를 갖는 fuzzy 제어기를 구성하였고 기존의 PI 제어기 를 사용한 시스템과 비교하였다.

실시간 제어를 위해 퍼지 입력변수 $e$ 와 $c e$ 를 각각 21 단계 로 양자화 하여, 각각에 대한 fuzzy 제어기의 출력 $F_{f u z z y}(e, c e)$ 을 계산, look-up table 형식으로 마이크로프로세 서 내에 저장하여 사용하였다.

본 논문에서 사용한 하드웨어의 전체적인 구성은 그림 7 과 같이 구성을 하였으며 위치 센서인 증분형 엔코더에서 나온 펄스로 속도를 계산하였고 $\mathrm{EPROM}$ 에 저장된 데이터를 이용해 각도제어를 하였다. 또한 SRM 구동용 컨버터로는 전류제어형 비대칭브리지 컨버터를 구성하였으며 히스테리 시스 전류제어기를 설계하였다.

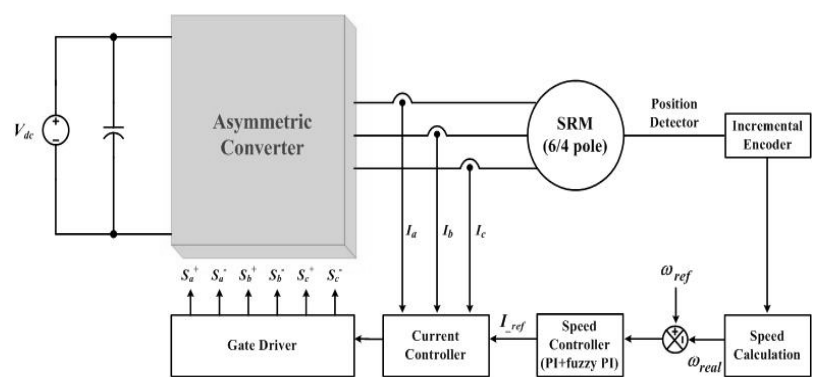

그림 $7 \mathrm{SRM}$ 구동시스템

Fig. 7 Driving system of SRM

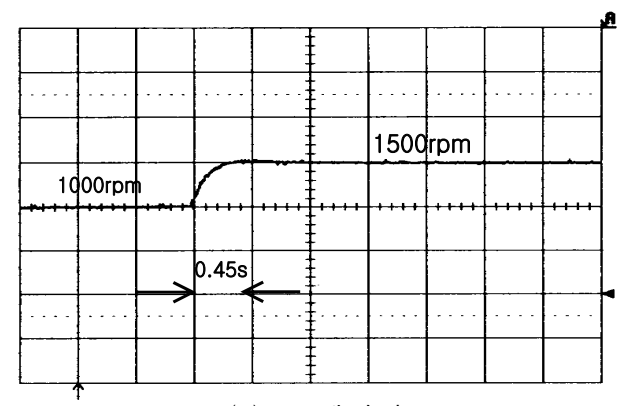

(a) $\mathrm{PI}$ 제어기

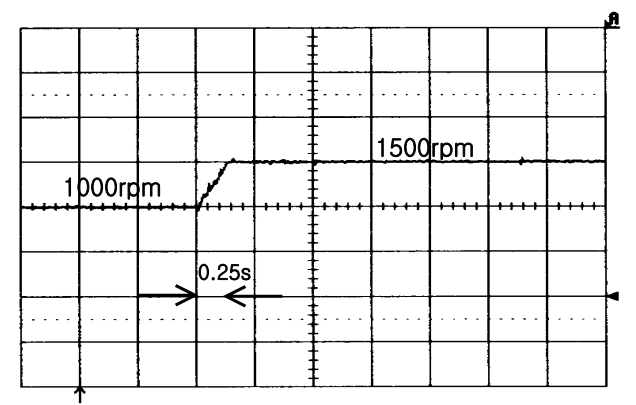

(b) $\mathrm{PI}+$ fuzzy 제어기

그림 8 속도 변화시의 속도응답 $(0.5 \mathrm{~s}, 500 \mathrm{rpm} / \mathrm{div}$.)

Fig. 8 Speed response during variable speed operation $(1000 \mathrm{rpm} \rightarrow 1500 \mathrm{rpm})$ 
그림 8 은 무부하시 $1,000 \mathrm{rpm}$ 에서 $1,500 \mathrm{rpm}$ 으로 속도 지 령치 변화에 대한 속도응답 파형이다. PI 제어기를 사용한 경우 정상상태까지 약 0.45 초가 소요되었지만, PI + fuzzy 제어기는 약 0.25 초의 시간만에 오버슈트가 거의 없이 정상 상태에 도달하는 결과를 보여주고 있다.

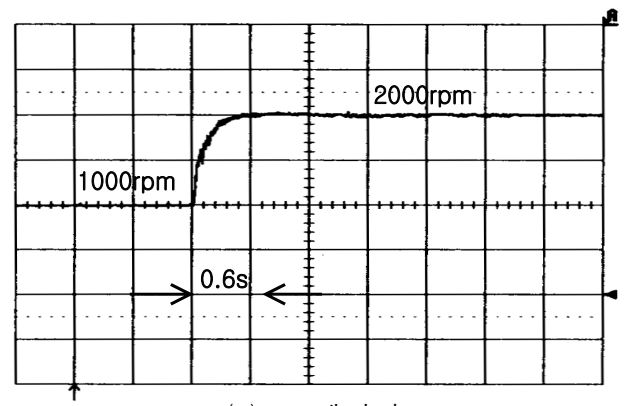

(a) $\mathrm{Pl}$ 제어기

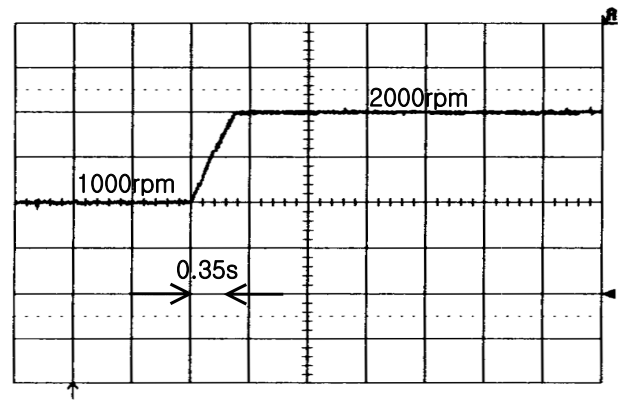

(b) $\mathrm{PI}+$ fuzzy 제어기

그림 9 속도 변화시의 속도응답 $(0.5 \mathrm{~s}, 500 \mathrm{rpm} / \mathrm{div}$.)

Fig. 9 Speed response during variable speed operation $(1000 \mathrm{rpm} \rightarrow 2000 \mathrm{rpm})$

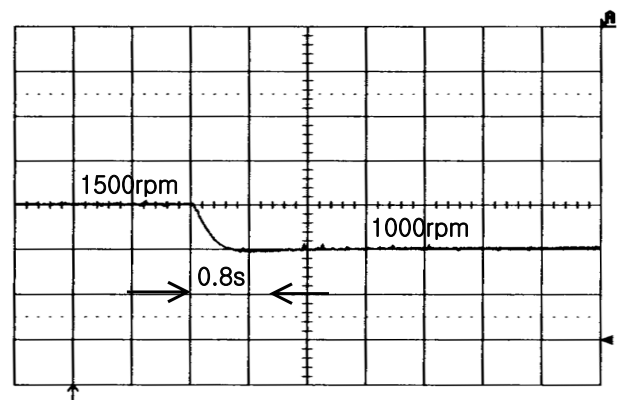

(a) $\mathrm{PI}$ 제어기

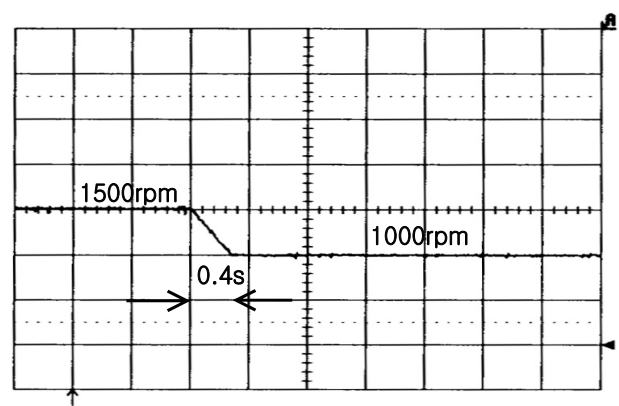

(b) $\mathrm{PI}+$ fuzzy 제어기

그림 10 속도 변화시의 속도응답 $(0.5 \mathrm{~s}, 500 \mathrm{rpm} / \mathrm{div}$.)

Fig. 10 Speed response during variable speed operation $(1500 \mathrm{rpm} \rightarrow 1000 \mathrm{rpm})$
그림 9 는 속도 지령치를 $1,000 \mathrm{rpm}$ 에서 $2,000 \mathrm{rpm}$ 으로 가 변시 속도응답 파형으로 PI 제어기를 사용한 경우 정상상태 까지 약 0.6초가 소요되었고, PI + fuzzy 제어기를 사용한 경우 약 0.35 초가 소요되고 있다.

그림 10은 속도 지령치를 $1500 \mathrm{rpm}$ 에서 $1000 \mathrm{rpm}$ 으로 감 속시 속도응답 파형으로 PI 제어기시 정상상태까지 약 0.8 초 가 소요되며, PI + fuzzy 제어기를 사용한 경우 오버슈트가 거의 없이 PI 제어기를 사용한 경우의 절반 수준인 0.4초 만 에 정상상태에 도달하는 결과를 보여주고 있다.

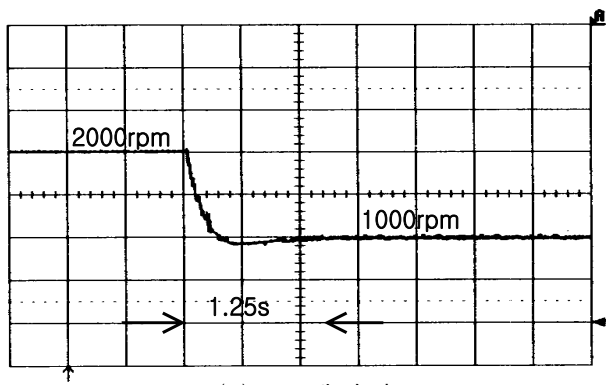

(a) $\mathrm{Pl}$ 제어기

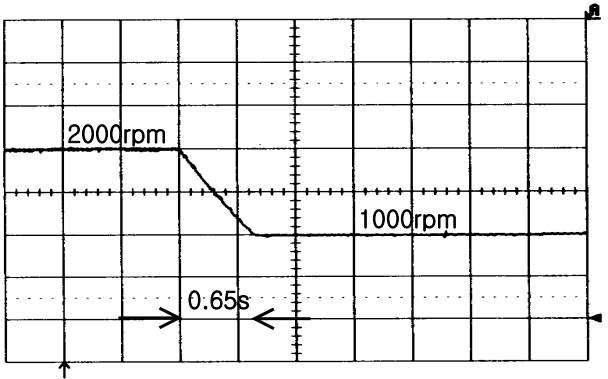

(b) PI + fuzzy 제어기

그림 11 속도 변화시의 속도응답 $(0.5 \mathrm{~s}, 500 \mathrm{rpm} / \mathrm{div}$.)

Fig. 11 Speed response during variable speed operation (2000rpm $\rightarrow 1000 \mathrm{rpm})$

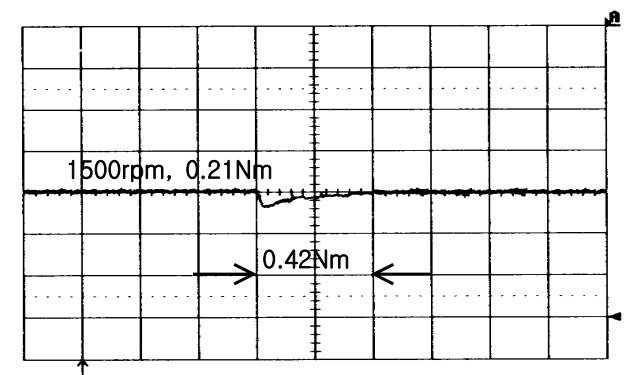

(a) $\mathrm{Pl}$ 제어기

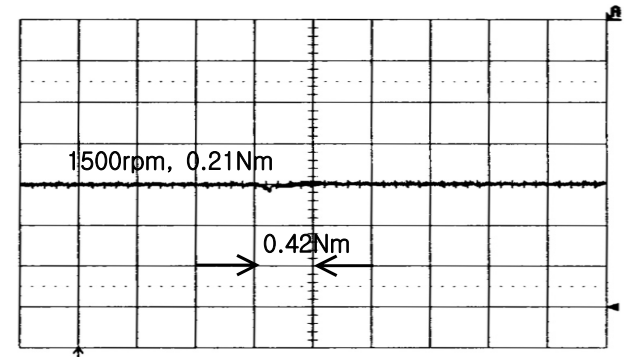

(b) PI + fuzzy 제어기

그림 12 부하증가시 속도응답 $(0.5 \mathrm{~s}, 500 \mathrm{rpm} / \mathrm{div}$.

Fig. 12 Speed response for load variation $(0.12[\mathrm{Nm}] \rightarrow 0.24[\mathrm{Nm}])$ 


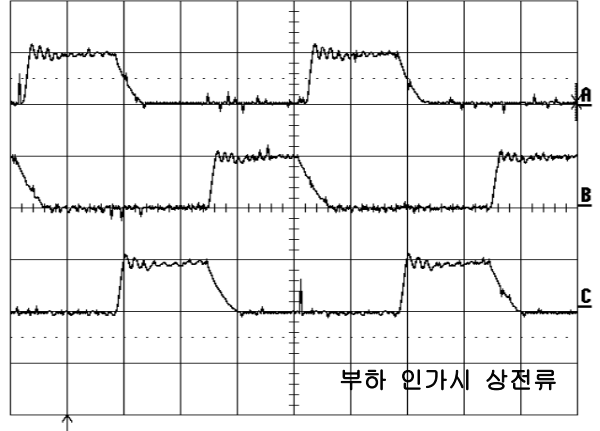

(a) $\mathrm{PI}$ 제어기(30W)

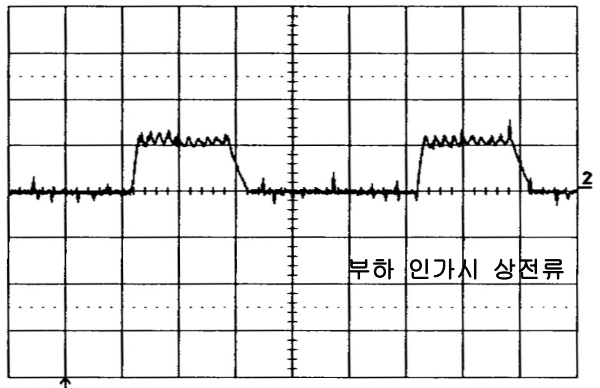

(b) $\mathrm{PI}+$ fuzzy 제어기(30W)

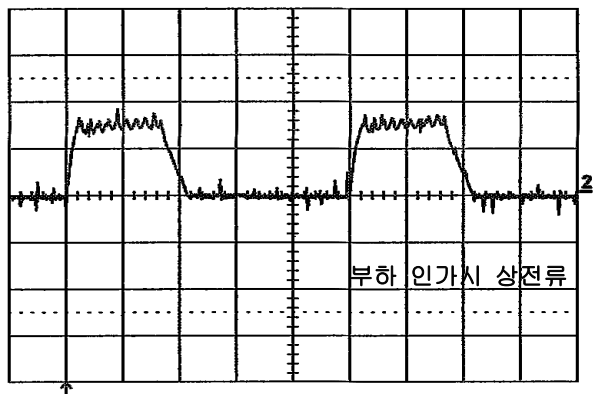

(c) PI + fuzzy 제어기 $(90 \mathrm{~W})$

그림 13 1000rpm시 전류파형(2ms, 5A/div.)

Fig. 13 Current waveform for 1000rpm

그림 11 은 속도 지령치를 $2,000 \mathrm{rpm}$ 에서 $1,000 \mathrm{rpm}$ 으로 감 속시 속도응답파형으로 PI 제어기를 사용한 경우 오버슈트 가 발생하면서 정상상태까지 도달시간이 1.25 초인 반면 $\mathrm{PI}$ + fuzzy 제어기 경우 오버슈트 없이 약 0.65초에 정상상태 에 도달함을 알 수 있다.

$\mathrm{PI}$ 제어는 일정한 파라미터를 가지는 선형 시스템과 고정 된 동작점에서 조정되는 시스템에서 유리하다. 그러나 실제 시스템에서는 시스템 고유의 비선형성들을 피할 수 없다. 본 논문에서는 $\mathrm{PI}$ 제어 이론을 $\mathrm{SRM}$ 드라이브 시스템에 적 용시켜 시뮬레이션 및 실험을 수행했으며 trial-and error 방 법이 최적제어 파라미터를 찾기 위해 사용되었다.

그림 12 는 $1,500 \mathrm{rpm}$ 으로 회전하는 도중 부하를 $0.21 \mathrm{Nm}$ 에서 $0.42 \mathrm{Nm}$ 로 부하변동시의 속도응답 파형이다. PI + fuzzy 제어기를 사용한 경우 순간적으로 플랜트의 제어입력 값을 크게 증가시켜 급격한 부하 변동에 대해서도 속도의 변화가 거의 없다. 그러나 PI 제어기를 사용한 경우 속도 오 차에 비례하는 제어값을 내보내기 때문에 급격한 부하변동
시 속도가 떨어지고 회복되기까지 시간이 상대적으로 오래 걸리는 결과를 보여주고 있다.

그림 13은 $1000 \mathrm{rpm}$ 으로 회전시 부하의 변동에 따른 정상 상태 전류파형에 대한 PI제어기와 PI + fuzzy 제어기의 결 과를 보여주고 있다.

본 논문의 전체적인 실험결과에서 PI + fuzzy 제어기를 사용한 가변속 시스템의 제어성능이 PI 제어기만을 사용한 시스템에 비하여 응답시간 및 부하변동시 응답성이 상대적 으로 우수한 결과를 보였다. 또한 오버슈트가 줄어들었고 부하변동에 대하여 강인한 성능과 감속시에도 우수한 특성 을 보여주고 있다.

\section{6. 결 론}

본 논문에서는 $\mathrm{SRM}$ 의 가변속 구동을 위해 일반적으로 사용되고 있는 PI 제어기와 PI + fuzzy 제어기의 응답특성 에 대해 비교하였으며 다음과 같은 연구결과를 얻었다.

(1) PI 제어기 경우 SRM의 비선형 인덕턴스 특성으로 인하 여 수학적 모델링이 불가능하기 때문에 최적의 제어 이 득값을 선정하기 어려운 점이 있다. 그러므로 제어 대상 의 수학적 모델링을 요구하지 않는 퍼지 알고리즘으로 제어기를 구성하여 PI 제어기에서 일반적으로 나타나는 오버슈트나 정상상태에서의 응답시간을 줄여주는 제어 성능의 향상을 확인하였다.

(2) PI + fuzzy 제어기를 최적의 제어 이득값을 PI 제어기와 비교한 결과 가변속 시스템의 응답시간의 단축과 오버 슈트가 거의 발생되지 않아 제어성능이 향상됨을 확인 하였다. 특히 부하의 가변시 강인한 특성을 보였고 감속 시 PI 제어기에 비해 우수한 제어 성능이 나타남을 확인 할 수 있었다.

\section{참 고 문 헌}

[1] Yan Yang, Zhiquan Deng, Gang Yang, Xin Cao, and Qianing Zhang, "A Control Strategy for Bearingless Switched-Reluctance Motors", IEEE Trans. on Power Electronics, Vol. 25, No. 11, pp.2807 2819, November 2010.

[2] Shi Wei Zhao, Norbert C. Cheung, Wai-Chuen Gan, and Jin Ming Yang, "High-Precision Position Control of a Linear-Switched Reluctance Motor Using a Self-Tuning Regulator", IEEE Trans. on Power Electronics, Vol. 25, No. 11, pp.2820 2827, November 2010.

[3] 김상훈, “DC, $\mathrm{AC}, \mathrm{BLDC}$ 모터제어”, 복두출판사, 2010.

[4] Jin-Woo Ahn and Dong-Hee Lee, "Characteristics Analysis of Suspending Force for Hybrid Stator Bearingless SRM", Journal of Electrical Engineering \& Technology Vol.6, No.2, pp.208 214, 2011.

[5] Chwan-Lu Tseng, Shun-Yuan Wang et al., "Development of a Self-Tuning TSK-fuzzy Speed Control Strategy for Switched Reluctance Motor", 
IEEE Trans. on Power Electronics, Vol. 27, No. 4, pp.2141 2152, April 2012.

[6] Sung-Jae Huh, Kyu-Dong Kim, Huh Uk-Youl Huh et al., "Fuzzy logic based control of high current SRM", Proceedings of the 41st SICE Annual Conference, pp.1216 1219, 2002.

[6] S.Makhloufi and R.Abdessemed, "Type-2 Fuzzy Logic Optimum PV/Inverter Sizing Ratio for Grid connected PV Systems: Application to Selected Algerian Locations", Journal of Electrical Engineering \& Technology Vol.6, No.6, pp.731 741, 2011.

\section{저 자 소 개}

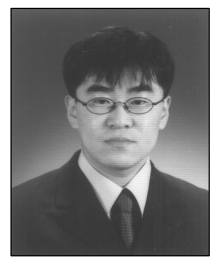

\section{윤 용 호 (尹 溶 湖)}

2002년 성균관대 메카트로닉스공학과 졸 업(석사). 2002년 2003년 LG전자 연구 원. 2007년 2월 동 대학원 졸업(공박). 2007년 2월 2011년 10월 삼성탈레스 기 술연구소 전문연구원. 2011년 10월 현재 한국산업기술시험원 신재생에너지평가센 터 선임연구원

Tel : 031-500-0327

Fax : 031-500-2511

E-mail : yhyoon@ktl.re.kr

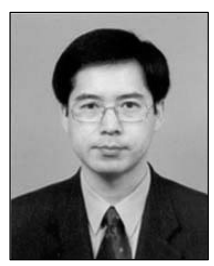

\section{박 준 석 (朴 峻 東)}

1987년 경북대학교 전기공학과 졸업. 1989 년 경북대 공대 대학원 전기공학과 졸업(석사). 2010년 중앙대 대학원 전기 공학과 졸업 (박사). 1991년 9월 현재 한국산업기술시험원 신재생에너지평가센 터 수석연구원

Tel : 02-860-1480

Fax : 02-860-1469

E-mail : jspark@ktl.re.kr

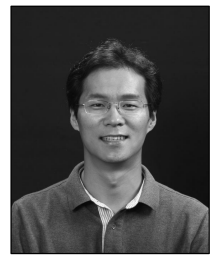

\section{송 상 훈 (宋 向 勳)}

영남대학교 전기공학과 졸업(학사). 2000 년 성균관대학교 공과대학 대학원 전기 공학과 졸업(석사). 2005년 동 대학원 전 기전자컴퓨터공학부 박사 수료. 2000년 현재 한국산업기술시험원 전기전자표준 센터장

Tel : 031-500-0250

Fax : 031-500-0258

E-mail : shsong@ktl.re.kr

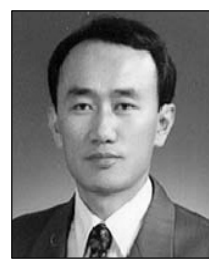

원 충 연 (元 忠 淵)

성균관대학교 전기공학과 졸업. 1980년 서울대 공대 대학원 전기공학과 졸업(석 사). 1987년 동 대학원 전기공학과 졸업 (박사). 1991년 12월 1992년 12월 미국 테네시 주립대학 전기공학과 방문교수. 1988 현재 한국 철도기술연구원 심사위

원. 2006년 현재 한국전력공사 PQ심사위원. 2006년 현 재 차세대 첨단도시철도시스템(한국건설교통기술평가원) 기술개발사업 운영위원. 현재 성균관대 정보통신공학부 교수.

Tel : 031-290-7115

Fax : 031-299-4623

E-mail : woncy@skku.edu

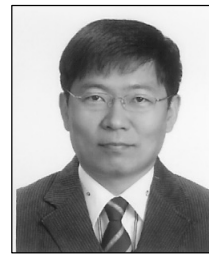

\section{김 재 문 (金 才 文)}

1994년 성균관대 전기공학과 졸업. 2000 년 2월 동 대학원 졸업(공박). 2000년 2004년 현대모비스(주) 기술연구소 선임 연구원. 2006년 현재 국토해양부 철도 기술 전문위원, 2004년 3월 현재 한국교 통대학교 철도전기전자공학과 부교수.

Tel : 070-8855-1664

Fax : 031-461-2944

E-mail : goldmoon@ut.ac.kr 